\title{
Antioxidant Activities of Sicilian Prickly Pear (Opuntia ficus indica) Fruit Extracts and Reducing Properties of Its Betalains: Betanin and Indicaxanthin
}

\author{
Daniela Butera, ${ }^{\S}$ Luisa Tesoriere,$\S$ Francesca Di Gaudio, \\ Antonino Bongiorno, ${ }^{\ddagger}$ Mario Allegra, ${ }^{\S}$ Anna Maria Pintaudi, ${ }^{\S}$ \\ RoHn KoHEN, ${ }^{\#}$ AND Maria A. LIVREA*,
}

\begin{abstract}
Departments of Pharmaceutical, Toxicological and Biological Chemistry, and Medical Biotechnologies and Forensic Medicine, Policlinico, University of Palermo, 90134 Palermo, Italy, and Department of Pharmaceutics, School of Pharmacy, P.O. Box 12065, The Hebrew University of Jerusalem,
\end{abstract} Jerusalem 91120, Israel

\begin{abstract}
Sicilian cultivars of prickly pear (Opuntia ficus indica) produce yellow, red, and white fruits, due to the combination of two betalain pigments, the purple-red betanin and the yellow-orange indicaxanthin. The betalain distribution in the three cultivars and the antioxidant activities of methanolic extracts from edible pulp were investigated. In addition, the reducing capacity of purified betanin and indicaxanthin was measured. According to a spectrophotometric analysis, the yellow cultivar exhibited the highest amount of betalains, followed by the red and white ones. Indicaxanthin accounted for about $99 \%$ of betalains in the white fruit, while the ratio of betanin to indicaxanthin varied from 1:8 $(w: w)$ in the yellow fruit to $2: 1(w: w)$ in the red one. Polyphenol pigments were negligible components only in the red fruit. When measured as 6-hydroxy-2,5,7,8-tetramethylchroman-2-carboxylic acid (Trolox) equivalents per gram of pulp, the methanolic fruit extracts showed a marked antioxidant activity. Vitamin C did not account for more than $40 \%$ of the measured activity. In addition, the extracts dose-dependently inhibited the organic hydroperoxide-stimulated red cell membrane lipid oxidation, as well as the metal-dependent and -independent low-density lipoprotein oxidation. The extract from the white fruit showed the highest protection in all models of lipid oxidation. Purified betanin and indicaxanthin were more effective than Trolox at scavenging the $\left[2,2^{\prime}\right.$-azinobis(3-ethylbenzothiazoline6 -sulfonic acid)] diammonium salt cation radical. Cyclic voltammetric measurements show two anodic waves for betanin and indicaxanthin, and differential pulse voltammetry shows three anodic waves for betanin, with calculated peak potentials of 404,616, and $998 \mathrm{mV}$, and two anodic waves for indicaxanthin, with peak potentials of 611 and $895 \mathrm{mV}$. Betanin underwent complex formation through chelation with $\mathrm{Cu}^{2+}$, whereas indicaxanthin was not modified. These findings suggest that the above betalains contribute to the antioxidant activity of prickly pear fruits.
\end{abstract}

KEYWORDS: Betalains; natural antioxidants; low-density lipoprotein; prickly pear; betanin; indicaxanthin

\section{INTRODUCTION}

Evidence continues to emerge suggesting that components of fruits and vegetables may be protective against oxidative damage $(1-3)$. In addition to antioxidant vitamins and minerals, polyphenols and other non-nutrient compounds of vegetables and fruits have been recognized as potential factors which can be beneficial to human health (4-6). The prickly pear (Opuntia

* Address correspondence to Prof. Maria A. Livrea, Dipartimento Farmacochimico c/o Dipartimento di Scienze Farmacologiche, Via C. Forlanini, 1, 90134 Palermo, Italy. E-mail: mal96@unipa.it.

$\S$ Department of Pharmaceutical, Toxicological and Biological Chemistry, University of Palermo.

$\doteqdot$ Department of Medical Biotechnologies and Forensic Medicine, University of Palermo.

\# Department of Pharmaceutics, The Hebrew University of Jerusalem. ficus indica) is a member of the Cactaceae family and is widely distributed in Mexico, much of Latin America, South Africa, and the Mediterranean area. The nutritional properties of the fresh stems (cladodes) have long been known, and prickly pear is used also in traditional medicine for its hypoglycemic and hypolipidemic actions (7-9). In the industrialized countries of the Mediterranean area, cladodes are not a usual nutritional source for humans, but the fruits are largely consumed. Sicily ranks second among all countries in the world for producing and exporting prickly pear fruits.

The prickly pear fruits are characterized by various colors due to the combination of two betalain pigments, the purplered betanin and the yellow-orange indicaxantin (10-12, Figure 1). The yellow cultivar is the main cultivar in Sicily, accounting 


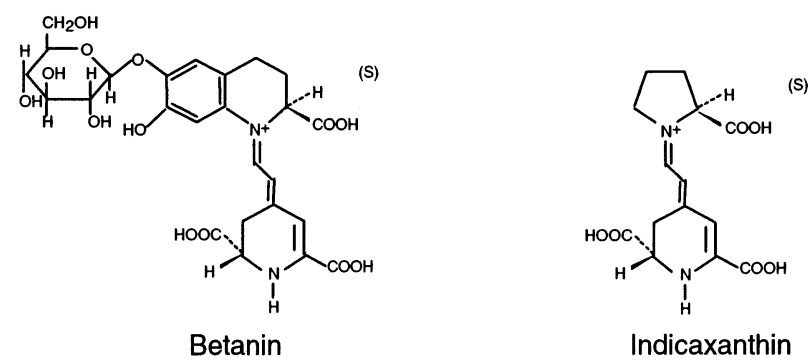

Figure 1. Chemical structures of betanin and indicaxanthin.

for almost $90 \%$ of the plantations, while the red and the white cultivars account for $10 \%$ and $2 \%$ of the plantations, respectively. Sweet and tasty fruits of prickly pear, ripening between the end of July and November, may be easily found as spontaneous vegetation, but products from cultivations are now usually marketed. The nutrients and chemical composition of the prickly pear fruit have been reported $(13,14)$. In contrast, though it is known that the fruit contains vitamin $\mathrm{C}(13,14)$, studies on other antioxidant components and on the antioxidant capacity are lacking. In this context, the characteristic pigments of the prickly pear should be taken into consideration. Betanin has recently been reported to possess antioxidant activity (15-17). Antioxidant properties of indicaxanthin, if any, are not known.

This study measured betalain compounds and investigated the antioxidant activity of aqueous extracts from the red, yellow, and white fruits of prickly pear from the Sicilian cultivars. Three established screening assays, i.e., the [2,2'-azinobis(3-ethylbenzothiazoline-6-sulfonic acid)] diammonium salt (ABTS) radical cation decolorization assay, the inhibition of the tert-butyl hydroperoxide-induced membrane lipid oxidation in human red blood cells, and the inhibition of the metal-dependent and -independent oxidative modification of human low-density lipoprotein (LDL), have been used. In addition, characterization of the isolated betanin and indicaxanthin, including measurement of their antioxidant potential as 6-hydroxy-2,5,7,8-tetramethylchroman-2-carboxylic acid (Trolox) equivalents (ABTS test), investigation of their ability to interact with $\mathrm{Cu}^{2+}$ ions, and cyclic voltammetric measurement of their redox potential, has been performed.

\section{MATERIALS AND METHODS}

Potassium persulfate, 1,1,3,3-tetraethoxypropane (TEP), ethylenediaminetetraacetic acid (EDTA), quercetin dihydrate, ascorbic acid, tertbutyl hydroperoxide, Sephadex G-25 (Fine), and 2,6-di-tert-butyl-4methylphenol (BHT) were from Sigma Chemical Co. (St. Louis, MO). Trolox and ABTS were from Aldrich Chemical Co. (Gillingham, UK). 2,2'-Azobis(2-amidinopropane)dihydrochloride (AAPH) was from Polyscience, Inc. (Warrington, PA). All other materials and solvents were of the highest purity or high-performance HPLC grade (Merck, Darmstadt, Germany).

Preparation of Fruit Extracts. Prickly pear fruits, collected in September-November 2001 in Sicily (Italy), were obtained from a local market and were processed within $48-72 \mathrm{~h}$ of collection. Four different lots of fruits, at comparable ripening stages, were analyzed for each cultivar. The fruits were peeled and finely chopped. The pulp was separated from the seeds and weighed, and 100-g pulp samples were homogenized with $100 \mathrm{~mL}$ of methanol. The mixtures were allowed to stand for $60 \mathrm{~min}$ at $4{ }^{\circ} \mathrm{C}$ before centrifugation $(10 \mathrm{~min}$ at $3000 \mathrm{~g}$ ). The organic layer was then recovered and the extraction repeated with the same volume of methanol. The combined extracts were subjected to rotary evaporation to remove the organic solvents. All the samples were portioned and stored at $-80^{\circ} \mathrm{C}$.

Lipid Oxidation in Red Blood Cells and in LDL. Blood samples were obtained from apparently healthy individuals by venipuncture, with informed consent. EDTA ( $1 \mathrm{mg} / \mathrm{mL}$ blood) was used as an anticoagulant. Red blood cells (RBCs) were sedimented at $1000 \mathrm{~g}$ for 10 min, and plasma was collected to isolate LDL (see below). RBCs were washed three times with phosphate-buffered saline (PBS), $\mathrm{pH}$ 7.4, and the supernatant and buffy coat were carefully removed by aspiration after each wash.

A $1 \%$ suspension of RBCs in PBS (HT 1\%) was incubated with 50 $\mu \mathrm{M}$ tert-butyl hydroperoxide at $37^{\circ} \mathrm{C}$, either in the absence or in the presence of variable amounts of methanolic extract of prickly pear fruits. At time intervals, malondialdehyde (MDA) was measured as an index of lipid oxidation. Briefly, $0.250 \mathrm{~mL}$ of the incubation mixture was mixed with $1.5 \mathrm{~mL}$ of hypotonic PBS, $0.250 \mathrm{~mL}$ of PBS, $5 \mu \mathrm{L}$ of 40 $\mathrm{mM}$ BHT, and $5 \mu \mathrm{L}$ of $1 \mathrm{M} \mathrm{NaOH}$. After cell homogenization, 0.250 $\mathrm{mL}$ of $0.6 \% \mathrm{TBA}$ in $35 \% \mathrm{HClO}_{4}$ was added, and the suspension was heated for $60 \mathrm{~min}$. Samples were then cooled and centrifuged at $1000 \mathrm{~g}$ for $10 \mathrm{~min}$, and the MDA-TBA adduct in the supernatant was separated by isocratic high-performance liquid chromatography (HPLC), performed on a Supelco Supelcosil LC-18 column $(0.46 \times 25 \mathrm{~cm})$. The eluent was $\mathrm{CH}_{3} \mathrm{CN} / \mathrm{H}_{2} \mathrm{O}$ (70:30) at $1 \mathrm{~mL} \mathrm{~min}{ }^{-1}$. The MDA-TBA adduct was revealed spectrophotometrically at $532 \mathrm{~nm}$ and quantified by reference to a calibration curve of TEP submitted to the TBA colorimetric procedure.

LDL $(d=1.019-1.063 \mathrm{~g} / \mathrm{mL})$ was isolated from EDTA plasma by stepwise ultracentrifugation at $4{ }^{\circ} \mathrm{C}$ in a Beckman L8-70 M ultracentrifuge, fitted with a $50 \mathrm{Ti}$ rotor using potassium bromide for density adjustments, according to Kleinveld et al. (18). The LDL fraction was shown to be free of other lipoproteins by electrophoresis on agarose gel. EDTA and salts were removed from LDL by gel filtration on Sephadex G-25. Proteins were determined by the Bio Rad colorimetric method (19). LDL protein $(0.2 \mathrm{mg} / \mathrm{mL})$ was incubated in the absence or in the presence of methanolic extracts of prickly pear fruits, in oxygen-satured EDTA-free PBS, supplemented with $10 \mu \mathrm{M} \mathrm{CuCl}_{2}$ as a pro-oxidant, in a 1-mL quartz cuvette. LDL oxidation was followed by continuosly monitoring the formation at $37^{\circ} \mathrm{C}$ of conjugated diene (CD) lipid hydroperoxides at $234 \mathrm{~nm}(20)$.

In other experiments, $0.1 \mathrm{mg} / \mathrm{mL}$ LDL proteins were oxidized by $0.5 \mathrm{mM}$ AAPH, with all other conditions as described above.

Analysis of Polyphenols and Vitamin C. Methanolic extracts from $200 \mathrm{mg}$ of edible pulp were treated with ethyl acetate $(1: 4 \mathrm{v} / \mathrm{v})$ to separate polyphenol compounds from betalains. Spectrophotometric analysis between 200 and $600 \mathrm{~nm}$ was carried out, and flavonols were evaluated from the absorption peak at $360 \mathrm{~nm}$, using pure quercetin as a standard.

Evaluation of ascorbic acid in methanolic extracts was done by reversed-phase HPLC, with spectrophotometric revelation at $266 \mathrm{~nm}$, as reported by Lazzarino et al. (21) with minor changes. These included the length of the HPLC column $(25 \times 0.46 \mathrm{~cm})$ and isocratic elution with $10 \mathrm{mM} \mathrm{KH}_{2} \mathrm{PO}_{4}$ buffer, $\mathrm{pH} 7.0$, containing $1 \%$ methanol and 10 $\mathrm{mL} / \mathrm{L}$ tetrabutylammonium bromide, at $1.2 \mathrm{~mL} \mathrm{~min}{ }^{-1}$. The retention time of ascorbate was $5.3 \mathrm{~min}$. Quantitation was by reference to curves constructed with 5-100 ng of pure compound.

Quantitation of Betalains in Fruit Extracts. Betanin in the methanolic pulp extracts was spectrophotometrically evaluated by the absorbance at $536 \mathrm{~nm}$, using a molar extinction coefficient of 65000 (22). Owing to the overlapping of betanin absorbance with the absorbance of indicaxanthin at $482 \mathrm{~nm}$ [calculated $A_{482}$ (betanin) $=$ 30 900], the indicaxanthin concentration in crude extracts containing both pigments was calculated according to eq 1 :

$$
\text { [indicaxanthin] }(\mu \mathrm{M})=23.8 A_{482}-7.7 A_{536}
$$

This equation was obtained by applying algorithms based on the molar absorbance of indicaxanthin at $482 \mathrm{~nm}\left[A_{482}\right.$ (indicaxanthin) $=42600$; (10)] and of betanin at either $536(22)$ or $482 \mathrm{~nm}$.

Purification of Indicaxanthin and Betanin. Betanin and indicaxanthin were separated by gel filtration on a Sephadex G-25 column $(40 \mathrm{~cm} \times 2.2 \mathrm{~cm})$ according to Kanner et al. (17), with minor modifications. Briefly, aliquots of methanol extracts from $2 \mathrm{~g}$ of fresh pulp were eluted with $1 \%$ acetic acid. Fractions $(2.5 \mathrm{~mL})$ were collected and tested spectrophotometrically at 482 and $536 \mathrm{~nm}$ for the presence of indicaxanthin and betanin, respectively $(10,11)$. The elution profile 
provided evidence that complete separation of the two pigments was achieved. The isolated pigments were submitted to high-performance liquid chromatography analysis on a Varian Microsorb C-18 column $(1 \times 25 \mathrm{~cm}$, Varian, Palo Alto, CA), eluted with a 20-min linear gradient elution from solvent A (1\% acetic acid in water) to $20 \%$ solvent B (1\% acetic acid in acetonitrile) at a flow rate of $2 \mathrm{~mL} / \mathrm{min}$ (12). Spectrophotometric revelation was at 536 and $482 \mathrm{~nm}$ for betanin (12.4 min) and indicaxanthin (13.6 min), respectively. A minor peak in the HPLC chromatogram, tentatively identified as isobetanin (13.3 min) (23), accounted for $0.5 \%$ of the isolated betanin. The elution volumes relevant to indicaxanthin and betanin were collected. Samples after cryoessiccation were resuspended in PBS at suitable concentrations for measurements of antioxidant potential and cyclic voltammetry.

Total Antioxidant Potential. The total antioxidant activity of either fruit extracts or purified pigments was evaluated using the ABTS radical cation decolorization assay (24). $\mathrm{ABTS}^{\bullet+}$ was prepared by reacting ABTS with potassium persulfate (25). Samples were analyzed in duplicate, at three different dilutions, within the linearity range of the assay. The assay was standardized with the synthetic antioxidant Trolox, and results were expressed as Trolox equivalents per gram of edible pulp or Trolox molar equivalents for fruit extracts or purified pigments, respectively.

Cyclic Voltammetry. A $100 \mu \mathrm{M}$ solution of either betanin or indicaxanthin in PBS was placed in a cyclic voltammeter cell, equipped with a working electrode $(3.3 \mathrm{~mm}$ in diameter, glassy carbon), a reference electrode $(\mathrm{Ag} / \mathrm{AgCl})$, and an auxiliary electrode (platinum wire). The potential was applied linearly to the working electrode at a constant rate $(50 \mathrm{mV} / \mathrm{s})$ toward the positive potential (evaluation of reducing equivalents). An electrochemical working station, CV-50W (Bioanalytical Systems, West Lafayette, IN), was used. During operation of the $\mathrm{CV}$, a potential current curve was recorded (cyclic voltammogram)

Copper Interaction Studies. The absorption spectra of purified betalains ( $2 \mu \mathrm{M}$ in saline) were recorded between 350 and $650 \mathrm{~nm}$. Scans with $1.0,2.0,4.0$, or $8.0 \mu \mathrm{M} \mathrm{CuSO}_{4}$ were taken and compared with the spectrum of betalain alone. The effect of 2.5 -fold excess EDTA concentration on the betalain-copper complex was examined.

Statistical Analysis. Conventional methods were used for calculation of means and standard deviations. Comparison between individual group means was performed by unpaired Student's $t$ test.

\section{RESULTS}

Pigments and Vitamin C from Opuntia ficus indica. The yellow indicaxanthin and the purple-red betanin are the characteristic pigments of the prickly pear. Spectrophotometric quantitation of these betalains has been reported for the yellow $(12)$ and red $(11,12)$ fruits. While measuring the pigments in the methanolic extracts from the white cultivar, we also reevaluated betanin and indicaxanthin in the red and yellow ones, by considering eq 1 to correct for the strong interference of betanin on the spectrophotometric indicaxanthin quantitation. The yellow cultivar shows the highest content of betalains, indicaxanthin accounting for $89 \%$ of the pigments. Betanin appears most concentrated in the red cultivar, accounting for about $66 \%$ of the betalains. Finally, the white cultivar shows the lowest content of betalains, and contains almost exclusively indicaxanthin (Table 1).

The amount of vitamin $\mathrm{C}$ in the aqueous extracts was similar for the three cultivars (Table 1).

The presence of polyphenols in the three cultivars of prickly pear was also checked. Spectral analysis of ethyl acetate extracts from the methanolic samples showed a small absorbance peak at $360 \mathrm{~nm}$ only in the extract from the red fruit, indicating the presence of flavonols (not shown). Using quercetin as a standard, an amount as low as $237 \pm 20 \mathrm{ng}$ of flavonols/100 $\mathrm{g}$ of pulp $(n=4)$ was calculated from the absorbance peak.

Antioxidant Capacity of Prickly Pear Fruit Extracts. Several approaches, in solution and in biological models, have
Table 1. Betalains and Ascorbic Acid in Sicilian Opuntia ficus indica Cultivars $^{a}$

\begin{tabular}{lccc}
\hline & \multicolumn{3}{c}{ content, $\mathrm{mg} / 100 \mathrm{~g}$ edible pulp } \\
\cline { 2 - 4 } & indicaxanthin & betanin & ascorbic acid \\
\hline yellow & $8.42 \pm 0.51$ & $1.04 \pm 0.12$ & $30 \pm 2.8^{b}$ \\
red & $2.61 \pm 0.30$ & $5.12 \pm 0.51$ & $29 \pm 1.7$ \\
white & $5.86 \pm 0.49$ & $0.10 \pm 0.02$ & $28 \pm 2.5$
\end{tabular}

${ }^{a}$ Each value is the mean \pm SD of four determinations performed in duplicate, on four lots of fruits. ${ }^{b}$ With respect to the red and white cultivars, $P=$ not significant.

Table 2. Total Antioxidant Activity of Methanolic Extracts from Prickly Pear Fruit and of Purified Betalains ${ }^{a}$

\begin{tabular}{lcr}
\hline & $\begin{array}{c}\mu \text { mol of Trolox equivalent/ } \\
\text { g of edible pulp }\end{array}$ & $\begin{array}{c}\text { Trolox } \\
\text { equivalents }\end{array}$ \\
\hline fruit extracts & $5.31 \pm 0.49^{b}$ & \\
yellow & $4.20 \pm 0.51$ & \\
red & $4.36 \pm 0.41$ & \\
$\quad$ white & & $20.0 \pm 0.5^{c}$ \\
pure compounds & & $1.76 \pm 0.1$ \\
$\quad$ betanin & & \\
indicaxanthin & & \\
\hline
\end{tabular}

${ }^{a}$ Each value is the mean $\pm S D$ of four determinations performed in duplicate, on four lots of fruits. ${ }^{b}$ With respect to the red and white cultivars, the value is significant with $\mathrm{P}=0.02 .{ }^{c}$ With respect to indicaxanthin, the value is significant with $\mathrm{P}<0.0001$.

been used to investigate the antioxidant potential of the prickly pear fruit. Hydrophilic extracts from the three cultivars were submitted to the ABTS radical cation decolorization assay (25), and the activities of the extracts, expressed as Trolox equivalents, are reported in Table 2 . On the basis of fresh weight, the total radical-scavenging ability of the methanolic extracts from the yellow fruit is significantly higher than the activity of the red and white ones.

Red blood cells exposed to organic hydroperoxides represent a useful model to study membrane lipid oxidation $(26,27)$. When RBCs (1\% HT) were incubated with $50 \mu \mathrm{M}$ tert-butyl hydroperoxide, time-dependent formation of MDA was observed, which reached a maximum value of $1.4 \pm 0.2 \mathrm{nmol} /$ $10^{6}$ cells after a 4-h incubation (not shown). Methanolic extracts from 1 to $5 \mathrm{mg}$ of edible pulp inhibited the MDA formed in 4 $\mathrm{h}$ in a dose-dependent manner (Figure 2). As a comparison, the antioxidant activity of $0.1-0.5 \mu \mathrm{M} \alpha$-tocopherol was assayed in the same system. Using $\alpha$-tocopherol as a reference, the white cultivar appeared as the most effective at inhibiting lipid oxidation, the extract from $1 \mathrm{mg}$ fresh pulp being as effective as $0.2 \mu \mathrm{M} \alpha$-tocopherol. Similar amounts of extracts from the red and yellow cultivars showed an antioxidant activity comparable to that of $0.13 \mu \mathrm{M} \alpha$-tocopherol (Figure 2).

Finally, the effect of methanolic extracts from $5 \mathrm{mg}$ of edible pulp on the time course of the $\mathrm{CD}$ hydroperoxide production in human LDL, submitted to either $\mathrm{Cu}^{2+}$ - or AAPH-mediated oxidation, was investigated. Figure 3 shows a typical experiment. In both models, the white cultivar was the most effective at enhancing the oxidation resistance, i.e., elongating the lag phase, followed by the red and the yellow ones. A concentrationdependent elongation of the lag phase was observed with the extracts from 1 to $5 \mathrm{mg}$ of edible pulp (Figure 3 insets).

Reducing Properties of Purified Betanin and Indicaxanthin. The radical-scavenging capacity of purified betanin and indicaxanthin was assessed by the interaction of either betanin or indicaxanthin with the ABTS cation radical, in comparison 


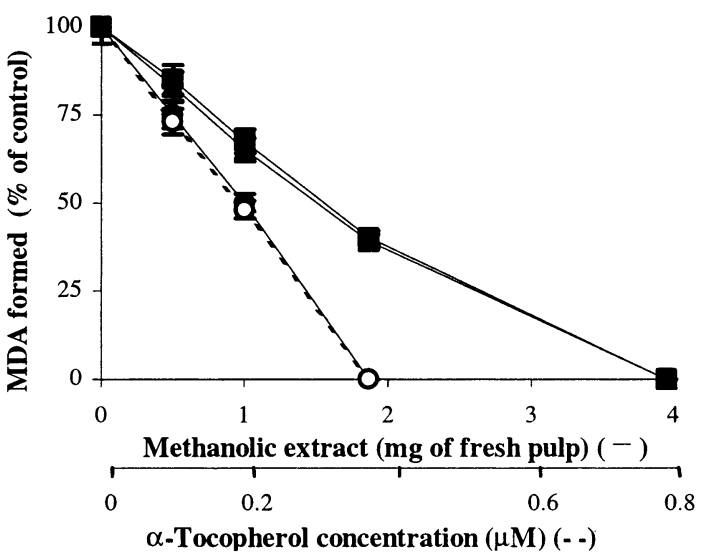

Figure 2. Dose-dependent inhibitory effect of methanolic extracts from fresh pulp of Opuntia ficus indica (full line) or $\alpha$-tocopherol (dotted line) on MDA formation in tert-butyl hydroperoxide-treated RBCs. Human RBCs (HT 1\%) were incubated with $50 \mu \mathrm{M}$ tert-butyl hydroperoxide at $37^{\circ} \mathrm{C}$ for $4 \mathrm{~h}$ in the absence (control) or in the presence of either $\alpha$-tocopherol $(\bigcirc)$ or methanolic extract of edible pulp from white $(\mathbf{O})$, yellow $(\mathbf{\Delta})$, and red (正 cultivars. MDA formation was determined as described in Materials and Methods and expressed as a percentage of the control. Each value is the mean $\pm S D$ of four determinations, performed in duplicate, with four lots of fruits.

with Trolox. Both betalains were highly effective, with betanin more active than indicaxanthin (Table 2).

The oxidation potentials of betanin and indicaxanthin were evaluated by $\mathrm{CV}$. The cyclic voltammogram for the two pigments shows two and three anodic waves for indicaxanthin and betanin, respectively, indicating that both are able to donate their electrons (Figure 4). Differential pulse voltammetry measurements, which were conducted in order to increase the sensitivity, show three anodic waves for betanin and two anodic waves for indicaxanthin. The peak potentials $\left[E_{\mathrm{p}(\mathrm{a})} \mathrm{s}\right]$ indicating the reducing power are 404, 616, and $998 \mathrm{mV}$ for betanin, while for indicaxanthin the values are 611 and $895 \mathrm{mV}$. The shape of the voltammetric waves toward the negative potential indicates that both compounds are irreversibly oxidized and their products can no longer accept electrons.

Copper Interactions. The interaction of either betanin or indicaxanthin with $\mathrm{Cu}^{2+}$ ions was assessed by visible spectroscopy at $\mathrm{pH}$ 7.4. A stepwise increment of $\mathrm{CuSO}_{4}$ concentration caused a shift in the absorption peak of betanin but did not have any effect on the absorption of indicaxanthin. The results are shown in Table 3. Interactions of $\mathrm{Cu}^{2+}$ ions with betanin $(2$ $\mu \mathrm{M})$ at $0.5: 1$ to $2: 1$ ratios produced a progressive hypsochromic shift from 536 to $520 \mathrm{~nm}$, which did not vary with further increments of $\mathrm{CuSO}_{4}$ (4:1 ratio). On addition of $20 \mu \mathrm{M}$ EDTA, the original spectrum was recovered (Figure 5).

\section{DISCUSSION}

Much research in recent decades has focused on the occurrence of antioxidant molecules, to find a link between diets rich in fruits and vegetables and the onset and/or prevention of a number of oxidative stress-related diseases $(28-31)$. Recent results showing that the regular ingestion of prickly pear cladodes is effective in lowering oxidation injury (32) suggest that there are effective antioxidant components in the edible tender stems of the plant. This study investigated, for the first time, the antioxidant capacity of the prickly pear fruit. Here we provide evidence that the aqueous extracts from the red, yellow, and white fruits from Sicilian cultivars possess a marked antioxidant activity.

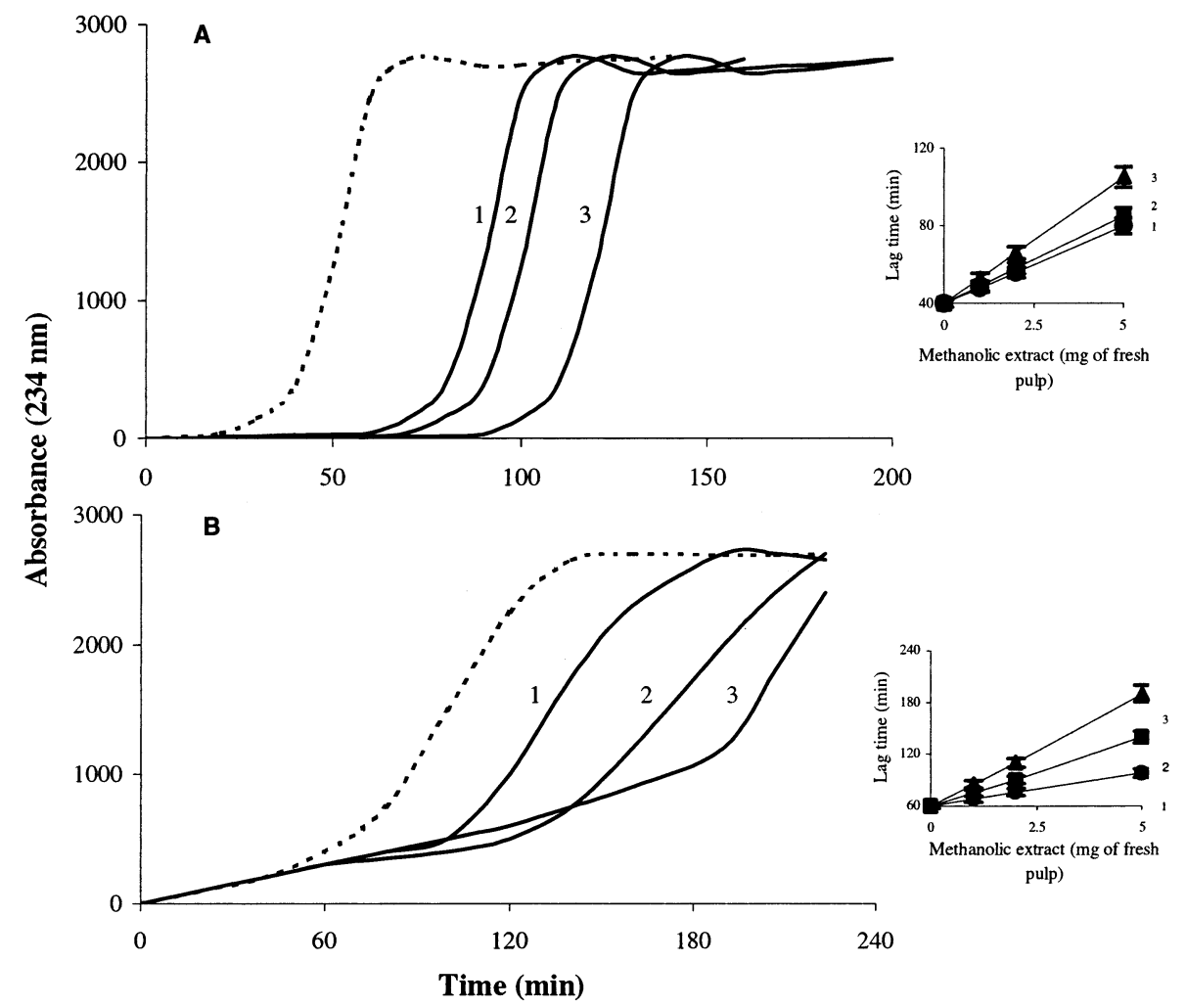

Figure 3. Time course of $C D$ hydroperoxide formation on oxidation of $L D L$ mediated by either $\mathrm{Cu}^{2+}(\mathrm{A})$ or $\mathrm{AAPH}(\mathrm{B})$ in the absence (dotted line) or in the presence (full lines) of methanolic extracts from $5 \mathrm{mg}$ of edible pulp of prickly pear. Inset: The dose-dependent effect of increasing concentrations of pulp in prolonging the lag time. 1, yellow cultivar; 2 , red cultivar; 3 , white cultivar. Each value is the mean \pm SD of four determinations performed in duplicate, with four lots of fruits. 

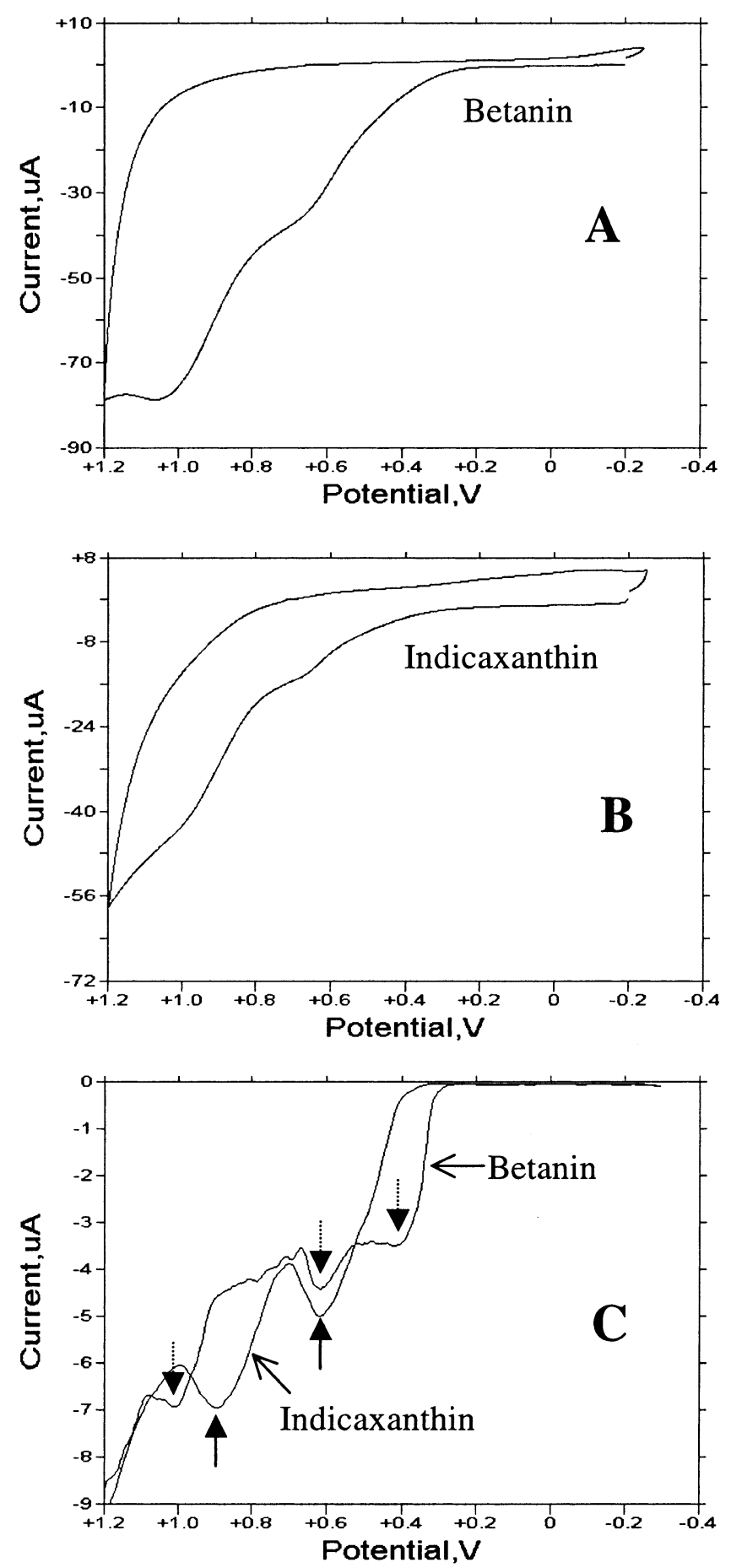

Figure 4. Cyclic and differential pulse voltammograms of betanin and indicaxanthin. Cyclic voltammetry measurements were carried out as described in Methods. Differential pulse voltammetry (DPV) was conducted at a scan rate of $50 \mathrm{mV} / \mathrm{s}$, pulse amplitude $50 \mathrm{mV}$, sample width $17 \mathrm{~ms}$, pulse width $50 \mathrm{~ms}$, pulse period $200 \mathrm{~ms}$. (A) Cyclic voltammogram of betanin. (B) Cyclic voltammogram of indicaxanthin. (C) DPV of betanin and indicaxanthin. The arrows represent the $E_{\mathrm{p}(a)}$ of the anodic waves.

Polyphenols are currently recognized as bioactive components of vegetables and fruits with antioxidant properties (4-6). Our analysis provided evidence that negligible amounts of polyphenols occur only in the red cultivar. As far as we know, dihydroquercetin and dihydrokaempferol have been identified by spectroscopic methods in the Opuntia ficus indica var. saboten, though the amounts have not been reported (33).
Table 3. Spectral Shifts of Betalains after Reaction with Increasing Concentrations of $\mathrm{CuSO}_{4}{ }^{\mathrm{a}}$

\begin{tabular}{lccccc}
\hline & \multicolumn{5}{c}{ peak position (nm) } \\
\cline { 2 - 6 } & & \multicolumn{4}{c}{$\begin{array}{c}\mathrm{Cu}^{2+} \text { :betalain } \\
\text { molar ratio }\end{array}$} \\
\cline { 2 - 6 } \multicolumn{1}{c}{ betalain } & control & $0.5: 1$ & $1: 1$ & $2: 1$ & $4: 1$ \\
\hline betanin & 536 & 533 & 530 & 520 & 520 \\
indicaxanthin & 482 & 482 & 482 & 482 & 482
\end{tabular}

${ }^{a}$ The concentration of each betalain was $2 \mu \mathrm{M}$. Data are representative of three experiments.

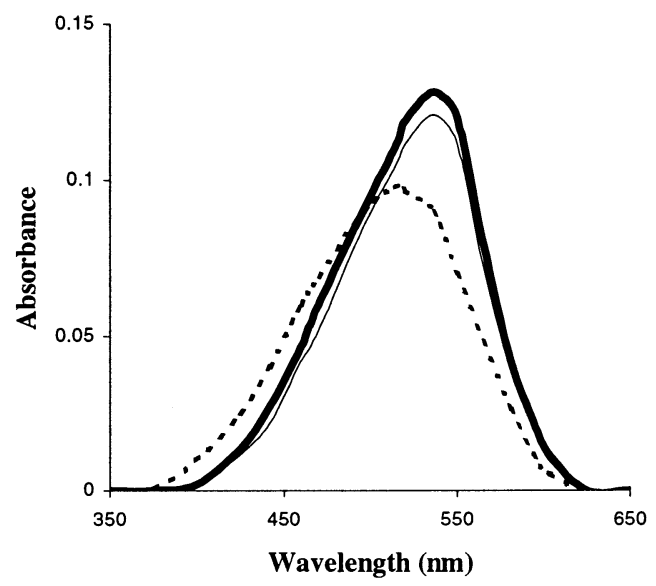

Figure 5. Effect of EDTA on $\mathrm{Cu}^{2+}$ chelate formation with betanin. Thick solid line, betanin $(2 \mu \mathrm{M})$; dotted line, betanin $(2 \mu \mathrm{M})$ plus $\mathrm{Cu}^{2+}(8 \mu \mathrm{M})$; thin solid line, betanin $(2 \mu \mathrm{M})$ plus $\mathrm{Cu}^{2+}(8 \mu \mathrm{M})$ after addition of EDTA $(20 \mu \mathrm{M})$.

Betanin, a betalain pigment, has recently been shown as an antioxidant in a number of model systems of lipid oxidation (17). Betalains such as betacyanins and betaxanthins occur in a number of natural sources; however, prickly pears, beets, and the fruit from vine cactus are the only foods containing this class of compounds $(22,34,35)$. Consistent with the results of others $(11,12)$, we found that betanin and indicaxantin are the main betalain pigments of the prickly pear. The yellow cultivar exhibits the highest amount of betalains, followed by the red and the white cultivars. The purple-red betanin was negligible in the white fruit, while the ratio betanin/indicaxanthin varied from 1:8 (w:w) in the yellow fruit to $2: 1(\mathrm{w}: \mathrm{w})$ in the red one. Other spectrophotometric measurements reported for the yellow (12) and the red cultivars $(11,12)$ do not appear to be in agreement with our findings. In particular, the ratio betanin/ indicaxanthin in the red cultivar has been reported as $1: 3$ (w:w) (11) or 2:3 (w:w) (12). This could not be considered correct. The application of the eq 1 , developed by considering the overlapping of betanin absorbance, may be recommended for the spectrophotometric evaluation of indicaxanthin in samples containing both pigments.

A global picture of the antioxidant potential of the watersoluble components of the prickly pear was achieved by measuring the ability of the methanolic extracts from the three cultivars to scavenge the ABTS cation radical in comparison with Trolox, the water-soluble analogue of vitamin $\mathrm{E}$. The quite high values measured with the three cultivars suggest the presence of very effective electron donors and/or H-atom donors. In accordance with the results of others (36), the prickly pear fruit appears to be a good source of vitamin C. Nevertheless, since the antioxidant capacity of $1.0 \mu \mathrm{mol}$ of vitamin $\mathrm{C}$ is 0.99 Trolox equivalents (37), the amount of vitamin $\mathrm{C}$ in the samples 
may account for only $30-40 \%$ of the total antioxidant activity of the fruit extracts. Other water-soluble compounds, including betalain pigments, may be considered. Our measurements with purified betanin and indicaxanthin provided evidence that both compounds have a marked antiradical activity against the ABTS cation radical, which may support a major role for betanin and indicaxanthin in the observed activity of the fruit extracts. Higher activity of betanin with respect to indicaxanthin was measured in the ABTS assay. The monophenol nature of betanin and reducing intermediates during the oxidation process $(38,39)$ may confer the molecule a higher $\mathrm{H}$-atom or electron donation potential. This appears also to be in agreement with the observed redox potential determined for the two compounds by cyclic voltammetry. Interactions between the two pigments can also be considered to account for the observed activity of the crude extracts.

The antioxidant potentials of vegetables and fruits measured by the ABTS assay are quite consistent with those measured by the ORAC assay (40). On this basis, the total antioxidant capacity of the methanolic extracts of the prickly pear fruits appears to be more than 2-fold that measured for pear, apple, tomato, banana, and white grape, and it is of the same order as pink grapefruit, red grape, and orange (41).

Methanolic extracts from the prickly pear fruits were found to be able to inhibit the organic hydroperoxide-stimulated red cell membrane oxidation. In addition, the pulp extracts inhibited both metal-dependent and -independent LDL oxidation. Although the antioxidant contribution of other compounds in the extracts cannot be ruled out, the observed activities of purified betalains suggest that these pigments may play a significant role in preventing lipid oxidation in our model systems. Due to the interactions between betanin and copper ions, metal chelation, or some interference with binding of copper ions to the apo-B (42), could play some role in the protection of the $\mathrm{Cu}^{2+}$ mediated oxidation of LDL by betanin-containing extracts. However, the marked antioxidant activity of the extracts in all models of lipid oxidation, including the AAPH-dependent LDL oxidation and the tert-butyl hydroperoxide-stimulated lipid oxidation in red blood cells, suggests that one or more of the components may act as efficient scavengers of oxygen-centered radicals. According to the cyclic voltammetry measurements, the reduction potential of both betanin and indicaxanthin would allow these compounds to reduce either lipoperoxyl or alkoxyl radicals (42). In addition, the voltammogram showed that the oxidized species from both pigments are no longer capable of recapturing electrons, i.e., becoming oxidants. It can also be mentioned that betalains are a class of cationized molecules with affinity for membrane moieties (17). This may be an excellent attribute for the antioxidant properties of mixtures containing these compounds.

Though the ABTS assay and the cyclic voltammetry measurements showed that indicaxanthin is a less potent reducing compound than betanin, it seems interesting that the methanolic extract from the white cultivar, virtually lacking betanin, exhibited the highest protective action in all models of lipid oxidation. This may suggest advantageous interactions of indicaxanthin in biological moieties. The redox chemistry and radical scavenging properties of indicaxanthin deserve to be more thoroughly investigated.

In conclusion, while showing that the aqueous extracts from the prickly pear fruit have a marked antioxidant activity in both chemical and biological systems in vitro, our findings suggest that the betalain pigments may be important antioxidant components to account for the observed activity. Betanin bioavailability has been explored (17). However, the present findings are not expected to be directly representative of biological effects because the bioavailability of other betalain pigments, as well as their in vivo interactions and metabolism, is not known. Our results, however, would encourage nutritional studies to assess the importance of prickly pear in the maintenance of health and disease prevention. A trial is currently in progress to study the eventual protection of the endogenous antioxidant systems and/or reduction of oxidative stress by the regular ingestion of prickly pear fruits.

\section{ABBREVIATIONS USED}

ABTS, [2,2'-azinobis(3-ethylbenzothiazoline-6-sulfonic acid)] diammonium salt; TEP, 1,1,3-tetraethoxypropane; AAPH, 2,2'azobis(2-amidinopropane)dihydrochloride; BHT, 2,6-di-tertbutyl-4-methylphenol; Trolox, 6-hydroxy-2,5,7,8-tetramethylchroman-2-carboxylic acid; $\mathrm{CD}$, conjugated diene; $\mathrm{CV}$, cyclic voltammetry; DPV, differential pulse voltammetry; EDTA, ethylenediaminetetraacetic acid; HPLC, high-performance liquid chromatography; LDL, low-density lipoproteins; MDA, malondialdehyde; PBS, phosphate-buffered saline; RBCs, red blood cells.

\section{LITERATURE CITED}

(1) Rice-Evans, C. A.; Miller, N. J. Antioxidants: the case of fruit and vegetables in the diet. Br. Food J. 1985, 97, 35-40.

(2) Ames, B.; Shigenaga, M. K.; Hagen, T. M. Oxidants, antioxidants and the degenerative disease of aging. Proc. Natl. Acad. Sci. U.S.A. 1993, 90, 7915-7922.

(3) Lampe, J. W. Health effects of vegetables and fruits: assessing mechanism of action in human experimental studies. Am. J. Clin. Nutr. 1999, 70, 475-490.

(4) Hertog, M. G. L.; Feskens, E. J. M.; Hollman, P. C. H.; Katan, M. B.; Kromhout, D. Dietary antioxidants, flavonoids and the risk of coronary heart disease: the Zutphen eldery study. Lancet 1993, 342, 1007-1011.

(5) Rice-Evans, C. A.; Miller, N. J.; Paganga, G. Antioxidant properties of phenolic compounds. Trends Plant Sci. 1997, 2, $152-159$.

(6) Peterson, J.; Dwyer, J. Flavonoids: dietary occurrence and biochemical activity. Nutr. Res. 1998, 12, 1995-2018.

(7) Frati, A. C.; Jimenez, E.; Ariza, C. R. Hypoglycemic effect of Opuntia ficus indica in non insulin-dependent diabetes mellitus patients. Phytother. Res. 1990, 4, 195-197.

(8) Hegwood, D. A. Human healthy discoveries with Opuntia sp. (prickly pear). Hort. Sci. 1990, 25, 1515-1516.

(9) Fernandez, M. L.; Lin, E. C.; Trejo, A.; McNamara, D. J. Prickly pear (Opuntia sp.) pectin reverses low-density lipoprotein receptor suppression induced by a hypercholesterolemic diet in guinea pigs. J. Nutr. 1992, 122, 2330-2340.

(10) Piattelli, M.; Minale, L.; Prota, G. Isolation structure and absolute configuration of indicaxanthin. Tetrahedron 1964, 20, 23252329.

(11) Forni, E.; Polesello, A.; Montefiori, D.; Maestrelli, A. Highperformance liquid chromatographic analysis of the pigments of blood-red prickly pear (Opuntia ficus indica). J. Chromatogr. 1992, 593, 177-183.

(12) Fernandez-Lopez, J. A.; Almela, L. Application of highperformance liquid chromatography to the characterization of the betalain pigments in prickly pear fruits. J. Chromatogr. 2001, 913, 415-420.

(13) El Moghazy, A. M.; El-Sayyad, S. M.; Abdel-Beky, A. M.; Bechait, E. Y. A phytochemical study of Opuntia ficus indica (L.) Mill cultivated in Egypt. J. Pharmacol. Sci. 1982, 23, 224254. 
(14) El Kossori, R. L.; Villaume, C.; El Boustani, E., Sauvaire, Y.; Mejean, L. Composition of pulp, skin and seeds of prickly pears fruit (Opuntia ficus indica sp.). Plant Foods Hum. Nutr. 1998, 52, 263-270.

(15) Escribano, J.; Pedrenp, M. A.; Garcia-Carmona, F.; Munoz, R. Characterization of the antiradical activity of betalains from Beta vulgaris L. roots. Phytochem. Anal. 1998, 9, 124-127.

(16) Zaharova, N. S.; Petrova, T. A. Relationship between the structure and antioxidant activity of various betalains. Prikl. Biochim. Microbiol. 1998, 34, 199-202.

(17) Kanner, J.; Harel, S.; Granit, R. Betalains-A new class of dietary cationized antioxidants. J. Agric. Food Chem. 2001, 49, $5178-$ 5185.

(18) Kleinveld, H. A.; Hak-Lemmers, H. L. M.; Stalenhoef, A. F. H.; Demaker, P. N. M. Improved measurement of low-density lipoprotein susceptibility to copper-induced oxidation: Application of a short procedure for isolating low-density lipoprotein. Clin. Chem. 1992, 38, 2066-2072.

(19) Bradford, M. M. A rapid and sensitive method for quantitation of microgram quantities of protein utilizing the principle of protein-dye binding. Anal. Biochem. 1976, 72, 248-254.

(20) Esterbauer, H.; Gebicki, J.; Puhl, H.; Jürgens, G. The role of lipid peroxidation and antioxidants in oxidative modification of LDL. Free Rad. Biol. Med. 1992, 13, 341-390.

(21) Lazzarino, G.; Di pierro D.; Gavazzi B.; Cerroni L.; Giardina B. Simultaneous separation of malondialdehyde, ascorbic acid, and adenine nucleotide derivatives from biological sample by ion-pairing high-performance chromatography. Anal. Biochem. 1991, 197, 191-196.

(22) Schwartz, S. J.; von Elbe, J. H. Quantitative determination of individual betacyanin pigments by high-performance liquid chromatography. J. Agric. Food Chem. 1980, 28, 540-543.

(23) Stintzing, F. C.; Schieber, A.; Carle, R. Identification of betalains from yellow beet (Beta vulgaris L.) and cactus pear [Opuntia ficus-indica (L.) Mill.] by high-performance liquid chromatography-electrospray ionization mass spectrometry. J. Agric. Food Chem. 2002, 50, 2302-2307.

(24) Miller, N. J.; Rice Evans, C. A. Spectrophotometric determination of antioxidant activity. Redox Rep. 1996, 2, 161-171.

(25) Pellegrini, N.; Re, R.; Yang, M.; Rice-Evans, C. Screening of dietary carotenoids and carotenoid-rich fruit extracts for antioxidant activities applying 2,2'-azinobis(3-ethylenebenzothiazoline-6-sulfonic acid) radical cation decolorization assay. Methods Enzymol. 1999, 299, 379-389.

(26) Trotta, R. J.; Sullivan, S. G.; Stern, A. Lipid peroxidation and hemoglobin degradation in red blood cells exposed to t-butyl hydroperoxide. Dependence on glucose metabolism and hemoglobin status. Biochim. Biophys. Acta 1981, 679, 230-237.

(27) Rice-Evans, C.; Baysal, E.; Pashby, D. P.; Hochstein, P. $t$-Butyl hydroperoxide-induced perturbations of human erythrocytes as a model for oxidant stress. Biochim. Biophys. Acta 1985, 28, 426-432.

(28) Ames, B. M. Dietary carcinogens and anticarcinogens: oxygen radicals and degenerative diseases. Science 1983, 221, 12561263.
(29) Knekt, P.; Järvinen, R.; Seppänen, R.; Rissanen, A.; Aromaa, A.; Heinonen, O. P.; Albanes, D.; Heinonen, M.; Pukkala, E.; Teppo, L. Dietary antioxidants and the risk of lung cancer. Am. J. Epidemiol. 1991, 134, 471-479.

(30) Gaziano, J. M.; Manson, J. E.; Branch, L. G.; Colditz, G. A.; Willett, W. C.; Buring, J. E. A prospective study of consumption of carotenoids in fruits and vegetables and decreased cardiovascular mortality in the elderly. Ann. Epidemiol. 1995, 5, 255260.

(31) Cook, N. C.; Samman, S. Flavonoids-Chemistry metabolism, cardioprotective effects, and dietary sources. J. Nutr. Biochem. 1996, 7, 66-76.

(32) Budinsky, A.; Wolfram, R.; Oguogho, A.; Efthiniou, Y.; Stomatopoulos, Y.; Sinzinger, H. Regular ingestion of Opuntia robusta lowers oxidation injury. Prostaglandins, Leukotrienes, Essent. Fatty Acids 2001, 65, 45-50.

(33) Jeong, S. J.; Jun, K. Y.; Kang, T. H.; Ko, E. B.; Kim, Y. C. Favonoids from the fruits of Opuntia ficus indica var. saboten. Kor. J. Pharmacogn. 1999, 30, 84-97.

(34) Jackman, R. L.; Smith, J. L. Anthocyanins and betalains. In Natural Food Colorants; Heandry, G. A. F., Houghton, J. D., Eds.; Chapman and Hall: London, U.K., 1966; pp 244-309.

(35) Wybraniec, S.; Platzner, I.; Geresh, S.; Gottlieb, H. E.; Haimberg, M.; Mogilnitzki, M.; Mizrahi, Y. Betacyanins from vine cactus Hylocereus polyrhizus. Phytochemistry 2001, 58, 1209-1212.

(36) Gurrieri, S.; Miceli, L.; Lanza, C. M.; Tomaselli, F.; Bonomo, R. P.; Rizzarelli, E. Chemical characterization of Sicilian prickly pear (Opuntia ficus indica) and perspectives for the storage of its juice. J. Agric. Food Chem. 2000, 48, 5424-5431.

(37) Rice-Evans, C.; Miller, N. J. Total antioxidant status in plasma and body fluids. Methods Enzymol. 1994, 234, 279-293.

(38) Escribano, J.; Pedren.o, M. A.; García-Carmona, F.; Muñoz, R. Characterization of the antiradical activiy of betalains from Beta vulgaris L. roots. Phytochem. Anal. 1998, 9, 124-127.

(39) Martín Parra, J.; Muñoz, R. An approach to the characterization of betanine oxidation catalyzed by horseradish peroxidase. $J$. Agric. Food Chem. 1997, 45, 2984-2988.

(40) Paganga, G.; Miller, N.; Rice-Evans, C. A. The polyphenolic content of fruit and vegetables and their antioxidant activities. What does a serving constitute. Free Rad. Res. 1999, 30, 153162.

(41) Wang, H.; Cao, G.; Prior, R. L. Total antioxidant capacity of fruits. J. Agric. Food Chem. 1996, 44, 701-705.

(42) Buettner, G. R. The pecking order of free radicals and antioxidants: lipid peroxidation, $\alpha$-tocopherol, and ascorbate. Arch. Biochem. Biophys. 1993, 300, 535-543.

Received for review May 23, 2002. Revised manuscript received August 30, 2002. Accepted August 30, 2002.

JF025696P 